\title{
NUMERICAL ANALYSIS OF THE RISK OF NECK INJURIES CAUSED BY IED EXPLOSION UNDER THE VEHICLE IN MILITARY ENVIRONMENTS
}

\author{
Agnieszka MACKIEWICZ*, Grzegorz SŁAWIŃSKI* ${ }^{*}$, Tadeusz NIEZGODA**, Romuald BĘDZIŃSKI \\ ${ }^{\star}$ Faculty of Mechanical Engineering, Department of Biomedical Engineering, University of Zielona Góra, \\ ul. Licealna 9, 65-417 Zielona Góra, Poland \\ ${ }^{* *}$ Faculty of Mechanical Engineering, Department of Mechanics and Applied Computer Science, Military University of Technology, \\ ul. Gen. S. Kaliskiego 2, 00-908 Warszawa, Poland
}

a.mackiewicz@ibem.uz.zgora.pl, grzegorz.slawinski@wat.edu.pl, tniezgoda@wat.edu.pl, r.bedzinski@ibem.uz.zgora.pl

received 11 November 2015, revised 11 November 2016, accepted 16 November 2016

\begin{abstract}
As a result of an explosion under a military vehicle, the risk of threat to life and health of the crew increases. Examination of this event in terms of the security of soldiers comes down to a complex analysis of the mutual interaction of the body of a soldier, seating and structural elements of the vehicle. As a result, shock wave impacts can cause tremor resulting from the construction of the vehicle and acceleration of the passenger's body. This study attempts to analyze the impact of an explosion of an improvised explosive device (IED) under the military vehicle with the risk of cervical spine injuries of soldiers. The analysis was carried out using numerical methods in the LS-DYNA program and was carried out taking into account the variable displacement values and acceleration recorded during thel explosion. The study used a model of the body of a soldier in the form of a Hybrid III 50th Male Dummy.
\end{abstract}

Key words: Cervical Spine, Dynamic Overload, Underbody Blast Loadings, Injury Risk Curves, Military Environments

\section{INTRODUCTION}

Analysis of data from the Military Institute of Medicine base indicates a large percentage of cervical spine injuries occurring in Polish soldiers serving in Afghanistan in the period from June 2010 to April 2014. In 91 incidents, 312 of soldiers were injured (18 dead), of which 69 incidents were caused by an explosion of improvised explosive devices (IEDs). In 44 explosions the shock wave effected soldiers moving in the Rosomak type wheeled Armored Personnel Carriers (APCs). More than one third of all injuries resulted from bruises, twisted, fractures and structural injuries of the spine. Fig. 1 illustrates the incidence of dysfunction at different levels of the spine.

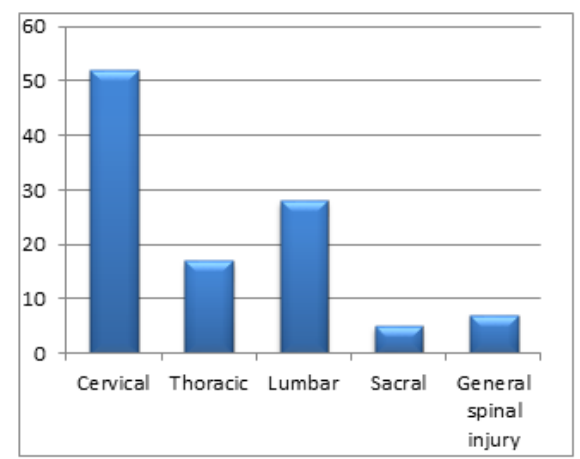

Fig. 1. The proportion of spinal dysfunction (Wojtkowski et al., 2014; Brzozowski et al., 2014)

The largest number of injuries occur in segments of the cervical spine, lumbar and thoracic (Wojtkowski et al., 2014,
Brzozowski et al., 2014). Military vehicles are exposed to the impact of a strong shock wave created by the explosion of explosive devices under the wheels, the hull or the side of the vehicle as well as sudden changes resulting in uncontrolled movement of unsecured items from inside the vehicle (Yang et al., 2013). The authors of various studies indicate that the high amplitude of shock waves caused by an explosion results in the effects of local and global construction of the vehicle. In the initial shock wave phase, acceleration increases until it contacts the bottom of the body followed by a contact, wave reflection and retransfer of the structure of the vehicle, wherein depending on the structure, elastic and plastic deformation is formed. High amplitude and short duration pulse impact acceleration cause the transfer of heavy loads by foot and pelvis to other body parts of soldiers, which takes about 50 milliseconds after detonation. The global effect is related to the energy absorbed by the vehicle emitted by the shock wave. Depending on the weight, the vehicle absorbs some of the energy - between 10 and $20 \mathrm{~ms}$, and the transporter begins to float, reaching a maximum peak height between 100 and $300 \mathrm{~ms}$. The impact of the explosion on the vehicle and the crew is shown in Fig. 2. During this incident the soldiers are mostly at risk of injury (Sławiński et al., 2013, Ramasamy et al., 2011, Heider et al., 2010, Krzystała et al., 2011a). Fig. 3 shows a snapshot of the AMV Rosomak after IED explosion under the hull of the vehicle (Slawinski's own resources, Afghanistan, 2012).

Seat belts are standard equipment of the seats in the AMV Rosomak, but the need for rapid entry and exit from the vehicle during a mission often means that soldiers ignore this protection. The aim of the study was to analyze the impact of the use of seat belts to the risk of cervical spine injuries to the driver and passengers of the military vehicle as a result of an explosion caused by overrunning onto an explosive device. 


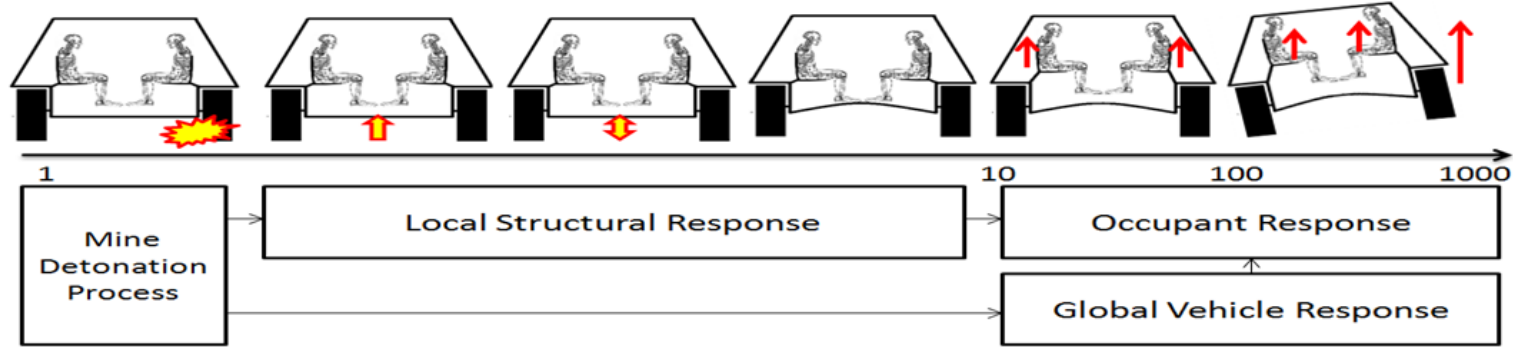

Fig. 2. The sequence of events during the detonation of an IED (Developed in accordance with HFM-090/TG-25, 2007, Krzystała et al., 2011b)

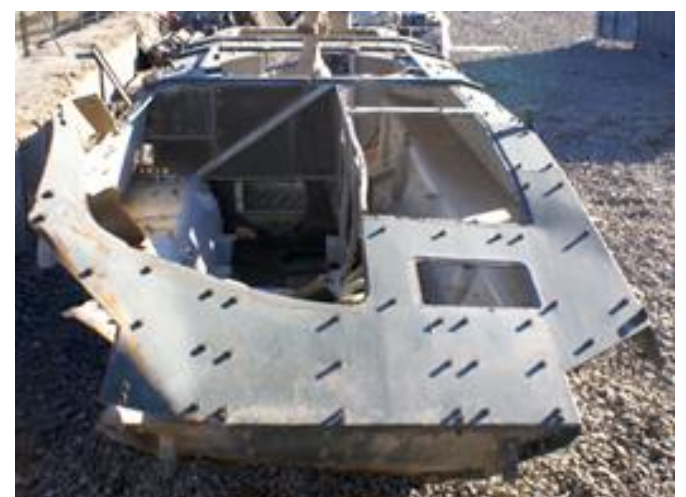

Fig. 3. AMV Rosomak after IED explosion (Slawinski's own resources, Afghanistan, 2012)

\section{METHOD}

The study attempts to assess the risk of cervical spine injuries of the driver and soldiers in the range of the AMV Rosomak armored amphibious assault vehicle caused by explosive mine under the right front wheel. The study was based on a dynamic numerical analysis in the LS-DYNA program using the explicit integration method to solve fast changing time problems. In the first step of research a simplified geometry of the AMV Rosomak vehicle was prepared (Fig. 4) having the correct distribution of seats, in the range of assault designed for soldiers-passengers (P2, P3, P4, P5) and in the driver's compartment (P1). The geometric model was digitized using four-node solid elements. In order to take into account the weight of the vehicle, a concentrated mass of main components: turret - $2900 \mathrm{~kg}$, drive unit 2200 $\mathrm{kg}$ and 8 of the wheels with a suspension of $270 \mathrm{~kg}$ per wheel was used in the model (Operating Instructions, description and use Rosomak 2005). The thickness of the painted steel sheet construction increased from 7 to $11 \mathrm{~mm}$. In order to obtain realistic weight of the AMV Rosomak of $22000 \mathrm{~kg}$, the density of the material was increased. In the model, the mass centre occurs as zerodimensional single-node elements. Absorption conditions were simulated to support the hull on a system of springs (three per wheel) with non-linear and asymmetrical characteristics.

The input data related to the movement of the vehicle needed to analyze body movements of soldiers in operating conditions were chosen based on the guidelines given by Nilakantan (2009). The output of the simulation obtained an explosion at the right front wheel, registering records of displacement measurement points in the time of $300 \mathrm{~ms}$. Building on a set of data provided by the Nilakantan et al (2009), forcing the vehicle was described as an impulse floor speed $-10.7 \mathrm{~m} / \mathrm{s}$. The chart of the command floor speed induced by the explosion of the load is shown in Fig. 5 (Nilakantan et al., 2009).

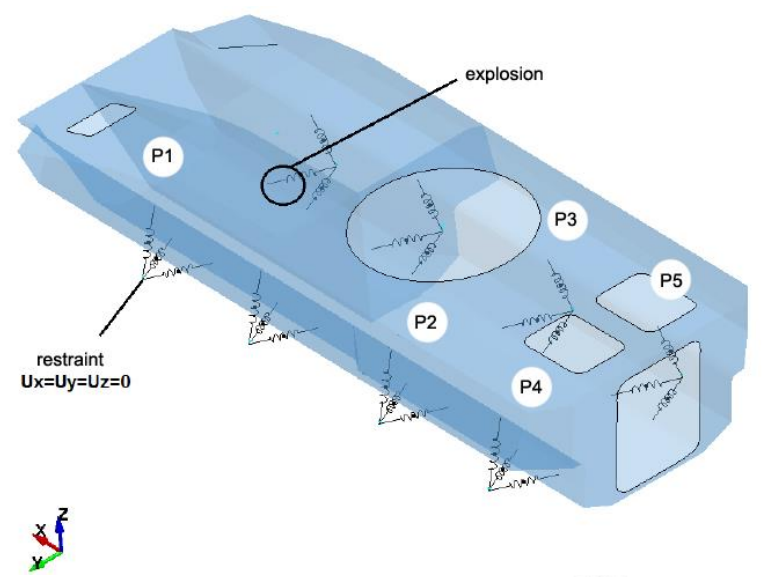

b)

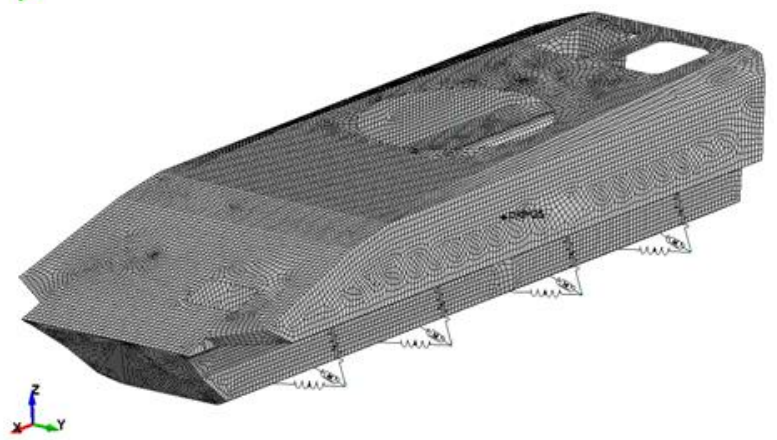

Fig. 4. Model of the AMV Rosomak: a) the distribution of passengerssoldiers in a three-dimensional coordinate system ( $\mathrm{x}$ - the direction of travel, $y$ - perpendicular direction to the direction of travel, $z$ - vertical direction), b) digitized model

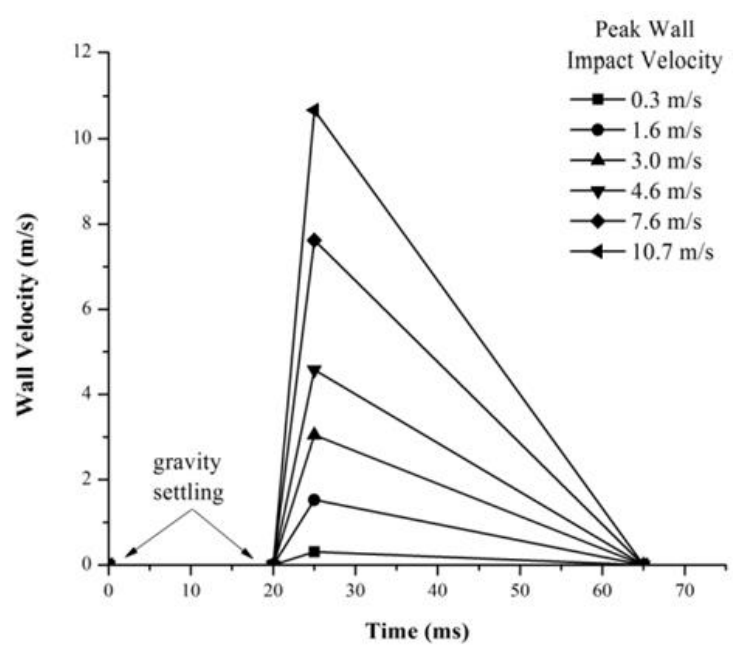

Fig. 5. Expected speed of the vehicle floor under the impulse of detonation (Nilakantan et al., 2009) 

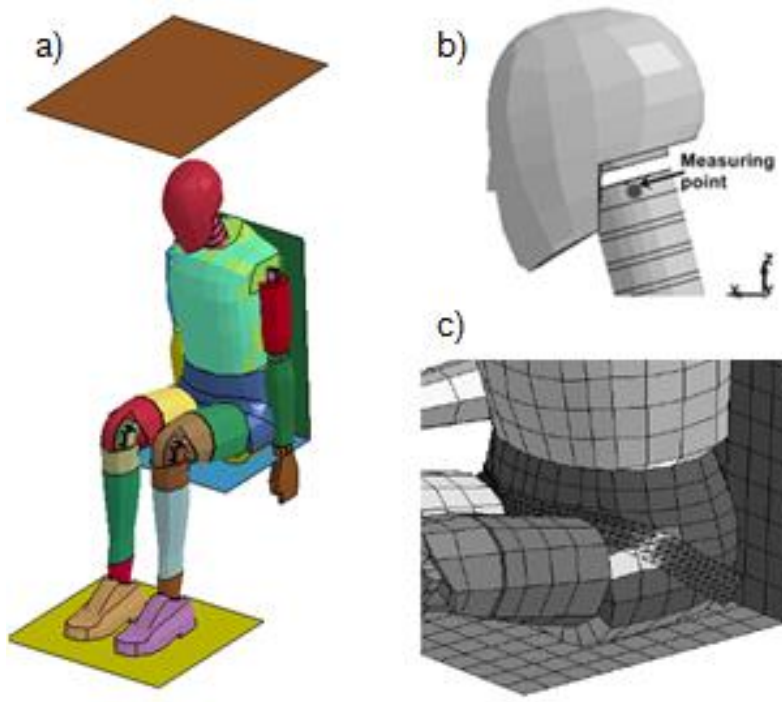

c)

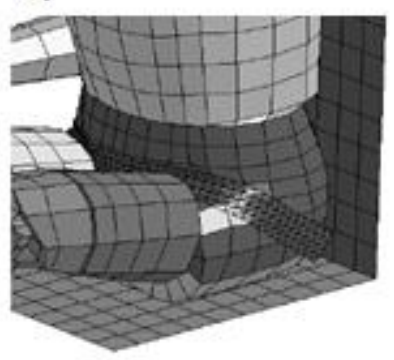

Fig. 6. Model: a) Mannequin type Hybrid III 50th Male Dummy, b) head and cervical spine indicating the measuring point, $c$ ) hip belt

In the second stage, the impact of detonating the load on the body of a soldier driving a combat vehicle was examined (P1) and two soldiers in the range of amphibious assault in extreme placement: P3-seating closest to the place of explosion and P4-seating situated furthest away from it. A variant of the fastened hip belt and its omission were considered for each of the cases (Fig. 6c). In the study the mannequin type model of a soldier used was the Hybrid III 50th Male Dummy (Fig. 6a).

During the analysis a change of acceleration and trajectory displacement of the measurement point located on the neck portion of the spine, at the height of the $\mathrm{C} 1$ circle with respect to the mounting points of the seat (Fig. 6b) in the coordinate system inside the vehicle at the time of $140 \mathrm{~ms}$ was recorded.

\section{RESULTS}

Analysis of the impact of detonation on wheeled APCs under the right front wheel showed significant displacement in the $Z$ vertical axis of $30 \mathrm{~cm}$ and a small rotation on the sides $(10 \mathrm{~cm})$ for both measuring points positioned on the floor and on the wall of the compartment of amphibious assault at an altitude of fastening the seat, which is shown in Figs. 7 and 8.

The results of the effect of the load detonation on the displacement of the soldiers' body are shown as characteristics depending on the $\mathrm{x}, \mathrm{y}, \mathrm{z}$ displacement components in time (Fig. 9). There are differences in the range of movements for each of the directions in the coordinate system of the vehicle on the graphs. In the case of the soldier driver (P1), the smallest movement of the cervical spine ranging up to a maximum of $100 \mathrm{~mm}$ was observed along the $y$-axis. This indicates that during the explosion under the right wheel, less displacement of driver to the side occurs. The largest absolute displacement value is present in the $x$ and $z$ direction. In driver (P1) with a fastened belt and without belts, large displacement in the $x$ direction can cause whiplash injury and spinal compression injury. Attaching the belt to the driver's seating during the event results in the displacement values in the $x$ direction not being characterized as linear, but wavy, which indicates a limitation of neck movement with the head and forcing their oscillatory motion.
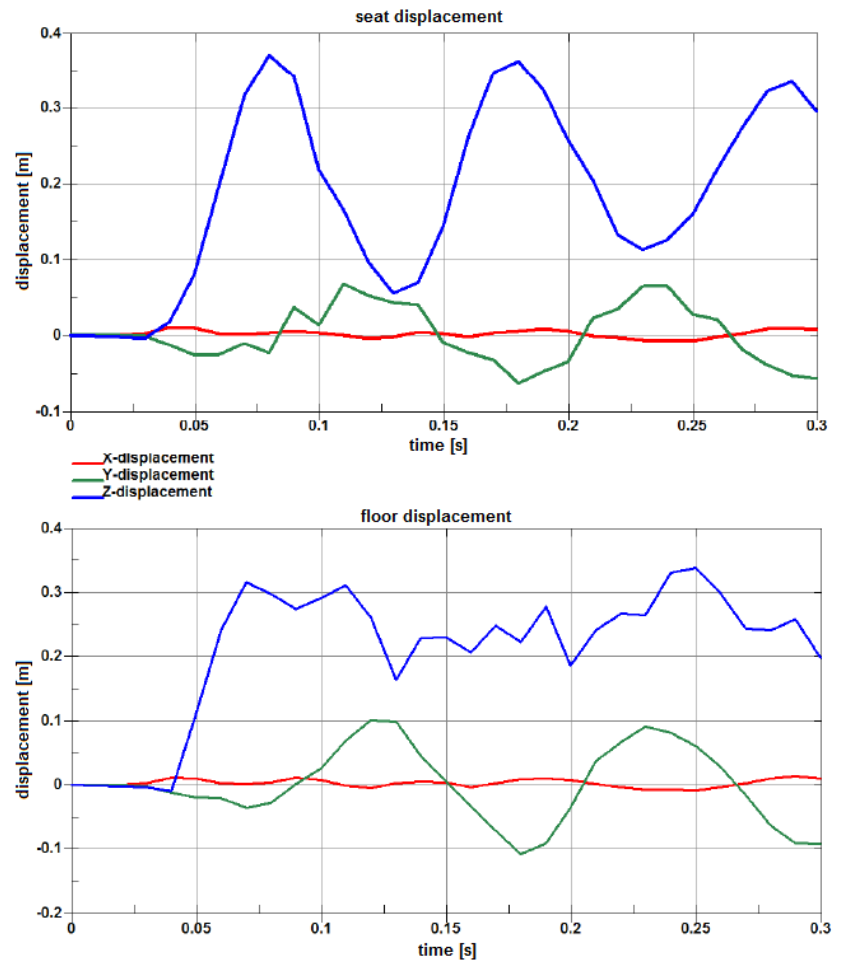

Fig. 7. Charts of displacement components of hull measuring point

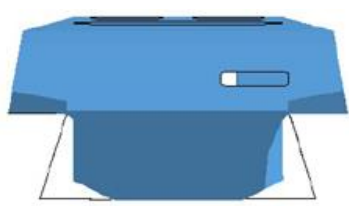

$\mathrm{t}=\mathbf{0} \mathrm{ms}$

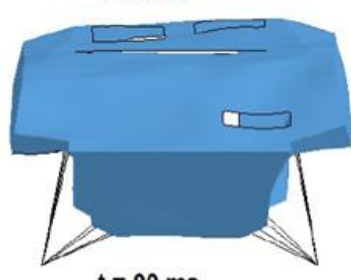

$\mathrm{t}=90 \mathrm{~ms}$

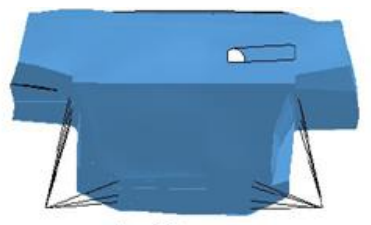

$\mathrm{t}=60 \mathrm{~ms}$

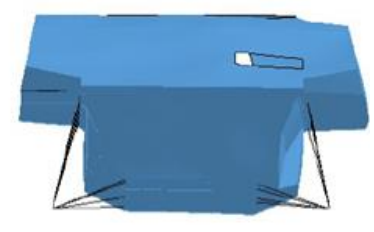

$\mathrm{t}=150 \mathrm{~ms}$
Fig. 8. Displacement of hull

In the P4 soldier (most distant from the place of explosion) with and without fastened belts, the component of displacement in the $x$-axis achieves peak values. Soldiers P3 and P4 are at higher risk of compression injuries associated with a shift in the $z$ direction. We observe the movement of both dummies in the $x$ direction as a consequence of the distribution of seats along the walls of the amphibious assault compartment and the slowdown of vehicle as a result of the explosion. As a result, it exposes the cervical spine to lateral bending. In the variant with a fastened seat belt, $x$ displacement reaches a value of approximately four times lower than displacement values when the belt is not fastened. In this case, changing the position of the measuring point on the neck of a soldier (P4) in the y direction has a value almost twice higher than for the P3 soldier. It is worth noting that the displacement in the case of the P4 soldier with a fastened seat belt has a positive and negative value which also indicates the possibility of flexion - hyperextension or flexion-rotational injury taking into account the displacement in the $\mathrm{x}$-axis. 
P1
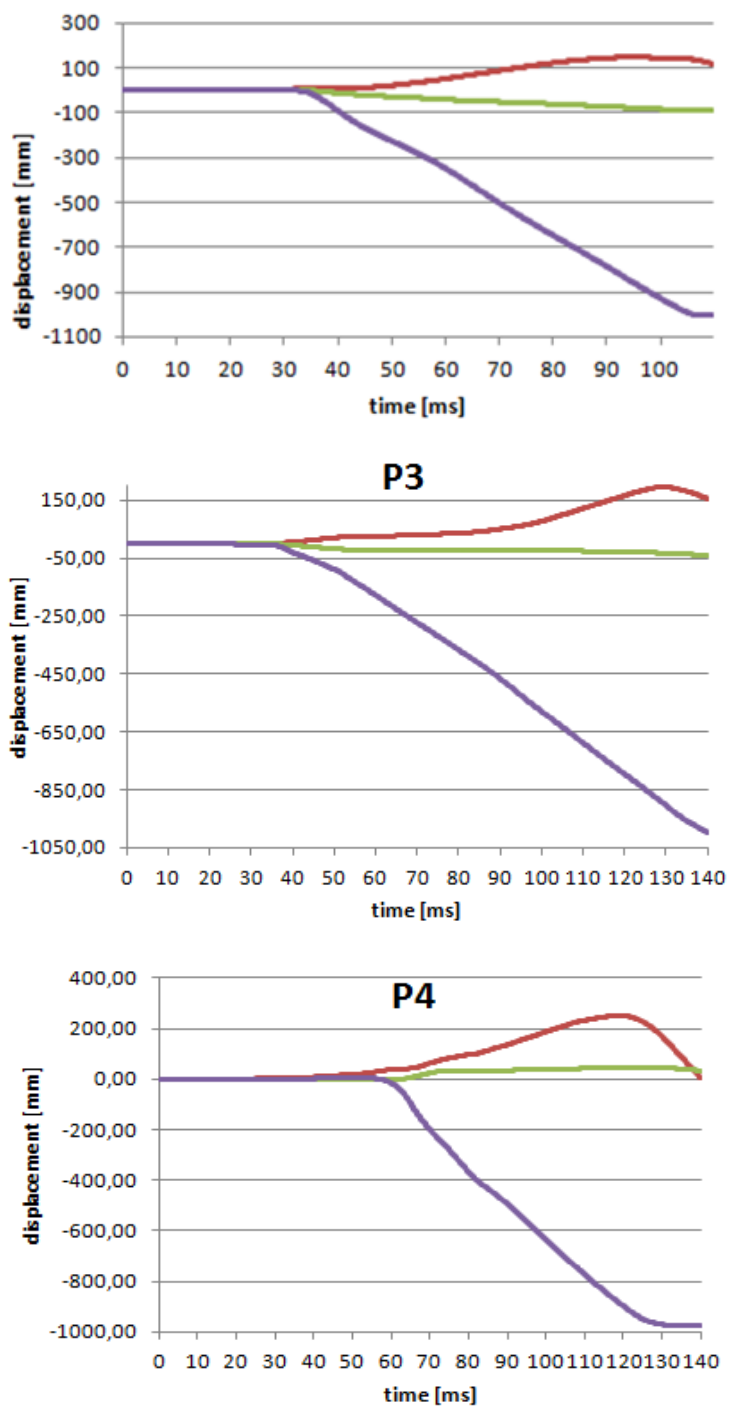

P1 with belt

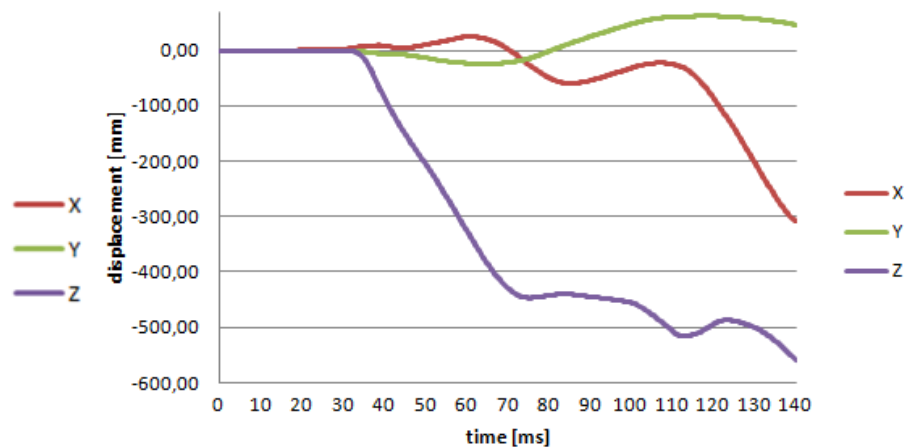

P3 with belt

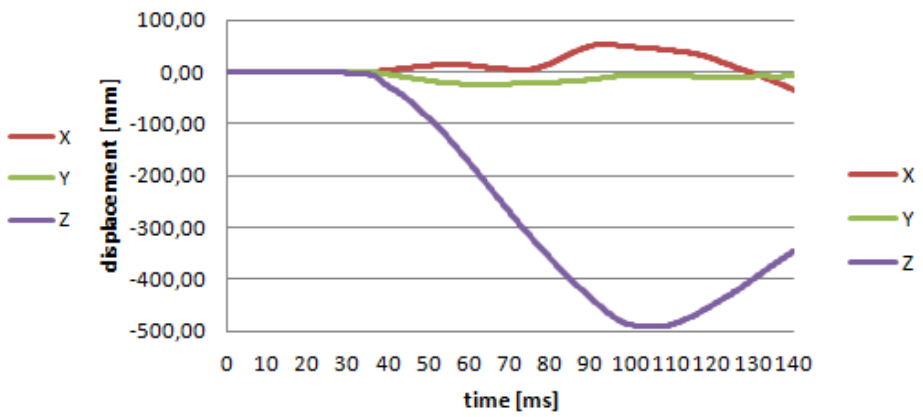

P4 with belt

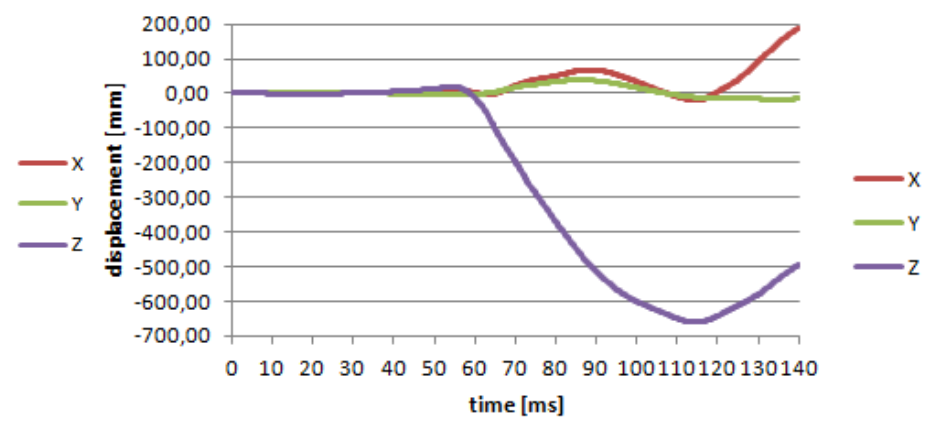

Fig. 9. Charts of displacement measuring points of driver dummies $P 1$ passengers P4 and P5 with and without seat belt in the co-ordinate system $\mathrm{x}$-direction of travel, $\mathrm{y}$-perpendicular direction to the direction of travel z-vertical direction
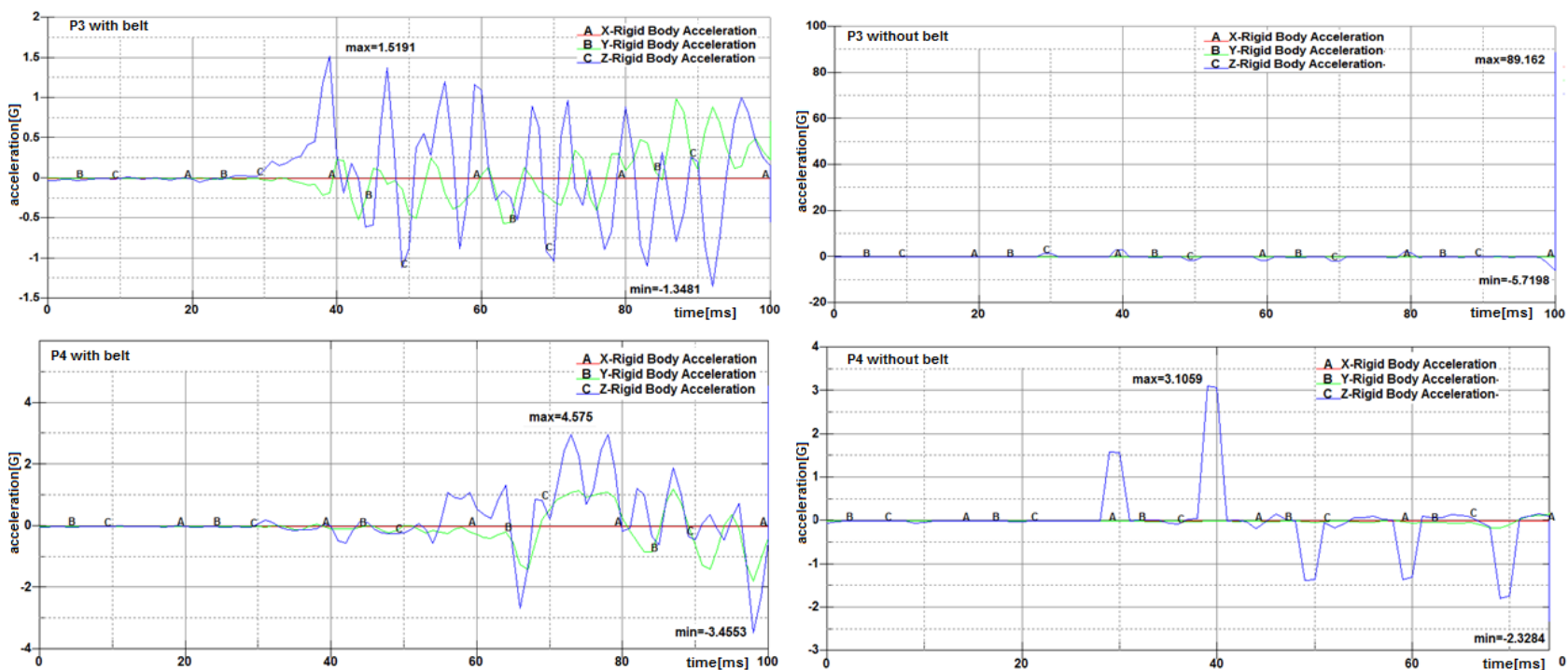

Fig. 10. Charts of acceleration measuring point of $\mathrm{P} 3$ and $\mathrm{P} 4$ dummies, with and without a seat belt 
The analysis of accelerations recorded at the point of measurement of the cervical spine for a P3 and P4 soldier (Fig. 10) showed the greatest acceleration in the direction of the z-axis. The greatest absolute accelaration values were reported in the P3 passenger without a seatbelt and it was almost 2 times higher than in the same case for the P4 passenger. The acceleration was recorded at $100 \mathrm{~ms}$, which, as confirmed by the analysis of the course of the shock wave is most likely to damage the anatomical structures. It is worth noting that the P4 passenger is located closest to the explosion site and receives the greatest acceleration from the floor and the affixed place of their seating. Recognizing the mechanism and direction of movement enables the prediction of possible traumatic changes in the neck column of soldiers exposed to the shock wave.

\section{DISCUSSIONS}

Injuries of passengers of military vehicles are the result of floor acceleration changes occurring as a result of pressure from the blast. The mechanism of compressive strength of the cervical spine is caused by exulting the soldier with the seat and his head hitting the roof of the vehicle. In analysing the cases of explosion in front part of the vehicle, it should be noted that the driven vehicle crashing into an explosive charge comes to a halt as a result and there is destabilization and displacement in the vertical or upright-side which was also observed in the test case. Doing so may prevent other traumatic mechanisms than only compression. It is important to study both displacements caused by the explosion and displacement transmitted through seats on the individual segments of the bodies of soldiers (Ramasamy et al., 2011). Three-dimensional analysis of the trajectory movement of each of the soldiers enables the probable dysfunction of the cervical spine caused by extortion as an IED explosion to be specified. The cervical spine is particularly susceptible to damage when the corps of the body relative to the neck is subjected to sudden acceleration or deceleration (Schmitt et al., 2010, Cronin, 2011). The results obtained in the course of research allow for the classification of cases with soldiers in two groups. The first one is a P1 soldier-driver, the other is a P3 and P4 amphibious assault soldier. The basis of classification is to consider the neck and head movement relative to the force derived from an IED explosion. In both cases there is a displacement of all the soldiers in the z-axis and $x$-axis, which is the direction of travel of the vehicle. The difference is the location of the seat relative to the direction of travel, wherein the P1 soldier is seated in the direction of driving, and in the perpendicular direction, additionally sitting opposite each other. The consequence of such an arrangement of seating is the back movement of the P1 driver, causing the forward bend and backward hyperextension in the sagittal plane in the case of belts fastened to the sides and flexion in the frontal plane for the P3 and P4 soldiers. For the the variant without belts, which forces oscillatory motion in the direction of the $x$-axis, displacement in accordance with only one vector - flexion of $\mathrm{P} 1$, and lateral bending one side of P3 and P4, is observed. Cronin (2014) describes the phases of whiplash injury in his work. Kinematic response of the cervical spine and head during this type of damage is reduced to generating "S" shape in the neck in the first phase, by withdrawing the lower vertebrae in the back (extension) and upper vertebrae with the head forward (flexion). Then there is movement of the head backwards and hyperextension as a result of inertia of the entire spinal column (Cronin, 2014). A similar trajectory can be observed in our case for the P1 soldier, so an accession of ligament damage which can cause instability is probability. The mechanism of whiplash injury may cause damage to both the back (PLL - posterior longitudinal ligament) and front (ALL - anterior longitudinal ligament) ligaments. Depending on the vector of the applied load during accelerated and delayed injury, it can include a hyper flexion mechanism (destruction of the LF Flavum Ligament and the ISL Interspinous Ligament) or hyperextension (destruction of the ALL anterior longitudinal ligament and tear of the FC Facet Capsule) (Ivancic et al., 2004, Panjabi et al., 2006). Leahny (2012) conducted an experimental and numerical simulation studying the impact of whiplash injury to the ligaments of the kinematics of the spine. The researcher found that damaged ligaments do not limit movement and are primarily responsible for the increase of its range, thus reducing stability. At the same time stating that after the simulation of whiplash injury, the relaxed ligaments force the necessity of using the same degree of clinical stabilization as in patients with completely torn structures (Leahy et al., 2012). Instability associated with dysfunction of the ligaments can lead to dislocation of the spine column (column buckling or fracture), thereby causing pressure on the nerve structures and vessels. As shown for each soldier, there is considerable displacement in the vertical axis $Z$, which increases the risk of the head hitting the roof of the vehicle. This results in a high probability of compression injury. According to the experimental studies of Denis (1983) compression fracture is located most often in the middle of the front of the vertebral body; however, it often comes up to the rear surface and the endplates, which may result in fragments penetrating deep into the spinal cord (Denis, 1983).

The type of dysfunction occurring on the traumatology base depends on where and how the tissue structures are load. Injuries of the upper segments are directly related to the force applied from the skull to the atlanto-occipital joint, and the lower segments are caused by impact forces directly to the vertebral body and the lever arm of force of several adjacent segments as in the case of P1 soldiers (Cusick et al., 2002). Similar conclusions were reached by Daffner (2006) and Robertson (2002) analyzing the cases in medical databases. The researchers showed that the fracture occurred at every level of the vertebrae, but the large majority of cracks occur in the extreme segments (Daffner et al., 2006, Robertson et al., 2002). The damage at these levels are usually caused by trauma on the mechanism of compression and flexion, causing comminuted fractures of the vertebral bodies (DeWit et al., 2012). According to Pintar (1998) in order to evaluate mechanisms of cervical injuries, the analysis of the rate of increase in the force and value and direction plays a key role. The researcher confirms that most of the damage of the cervical spine and the spinal cord is due to fractures and dislocations which are caused by the compression and flexion mechanism. Experimental studies determined that there is a $50 \%$ probability of damage at a load speed of $4.5 \mathrm{~m} / \mathrm{s}$ and achieving a force of $3.9 \mathrm{kN}$ (Pintar et al., 1998).

Experimental studies have shown that damage to the lower segments of the cervical spine occurs when the operating acceleration is in the range of $17-25 \mathrm{~g}\left(\mathrm{~g}=9.81 \mathrm{~m} / \mathrm{s}^{\wedge} 2\right)$. In the case of appreciable accelerations of $34-38 \mathrm{~g}$ it was noted that the resulting dysfunctions are located at the upper vertebrae and at the connection of the skull to the spine (Levine, 1994). Analysis of the studies of absolute acceleration values for a P3 and P4 soldier 
is in the range corresponding to Levine (1994) and the possibility of injuries in the lower segments of the cervical spine. The maximum acceleration values of $5.72 \mathrm{~g}$ were reported for a P3 soldier located on the seat closest to the explosion in the case of a hip belt not being fastened. In the case of a lap belt being fastened, acceleration in the z-axis was almost $75 \%$ lower. For a P4 soldier, the situation was opposite. In the variant of a fastened lap belt, acceleration in the z-axis was $30 \%$ higher than in the case of the hip belt being omitted. It should be noted that the explosion caused displacement for this passenger in the Z-axis of $150 \mathrm{~mm}$ higher than in variant despite a fastened seat belt.

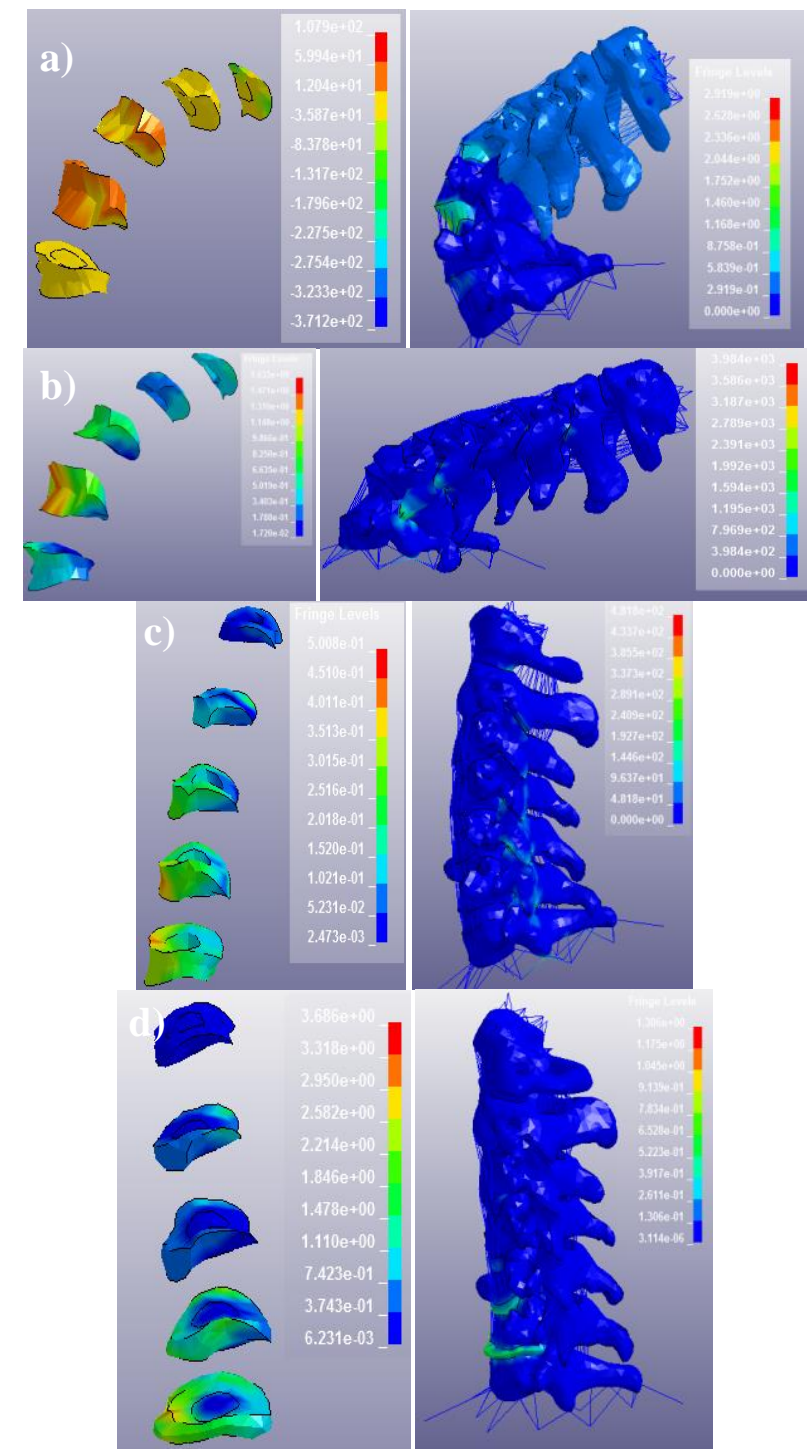

Fig. 11. The strain distribution in the intervertebral discs and spine column: a) P4 without belts, b) P4 with belts, c) P3 without belts, d) P3 with belts

Strain distribution as shown in Fig. 11 was analyzed for P3 and P4 soldiers. According to their placement, the biggest changes on the destructive ground occurred in the lower segments of the cervical spine, which were confirmed by the results obtained in the research of Levine (1994) (Levine, 1994). This was particularly noticeable in the structure of the $\mathrm{C} 5 \mathrm{C} 6$ and $\mathrm{C} 6 \mathrm{C} 7$ intervertebral disc. Bambach (2013) also conducted research on the impact of a passenger's head hitting the roof of the vehicle during a collision and the possibility of cervical spine injuries. The results obtained by the researcher are similar to results obtained in the study. Bambach (2013) states that most of the damage occurs at the level of $\mathrm{C} 5-\mathrm{C} 7$, and the mechanism of damage is compression with the head extension or lateral bending. As a result of these mechanisms, Bambach informs that fracture of the lamina vertebral, intervertebral joint dysfunction, anterior longitudinal ligament (ALL) and posterial longitudinal ligament dysfunction (PLL) most often occurs (Bambach et al., 2013).

Hryciów (2013) has sought to assess the level of dynamic loads acting on an armored personnel carrier and its crew during frontal collisions at low speeds. The study provides that there is a substantial threat to soldiers, resulting from the high level of load inertia during impact and deceleration of the vehicle in the way. As a result of experimental collision studies using dummies of the Hybrid III 50th Male dummy localized between the amphibious assault and the driver (all fastened in with a lap safety belt) the researcher analyzes the trajectory movement of soldiers. In the case of the driver, the maximum flexion of the cervical spine after $120 \mathrm{~ms}$ from the moment of impact is observed.

Due to the use of the safety belt, movement of the whole body is limited. After $340 \mathrm{~ms}$ from the moment of impact, the head is tilted up to the rear and the trunk is halted on the seat, which is characteristic in case of frontal collisions. Different behavior is observed for a dummy in range of amphibious assault. Approximately $220 \mathrm{~ms}$ after collision, maximum displacement of the dummy occurs. The trunk and head are first bent to the right, with the simultaneous forward inclination and slight rotation of the vertical axis. Hryciów notes the displacement acting on the neck of the dummies during the 5 trials, which are in the range 2.44$5.97 \mathrm{~g}$ are similar to results obtained by us for P3 and P4 soldiers (Hryciów et al., 2013).

It is worth noting that the highest probability of compression injury occurred in the P3 soldier without belts with whom we recorded the biggest acceleration in the $x$-axis of up to a value of nearly $90 \mathrm{~g}$. This fact can be explained by the smallest distance of the seat in relation to the explosion site.

Vertebral fractures are combined with application of variable force and hence Yogananda and Stemper (2013) drew attention to the issue of the vertical load of cervical spine in relation to combat injuries. The basis of their study was to measure the force acting on the vertical axis of the cervical spine during the compression and swinging impact, and effect of dynamic loads on the spine intact. Injuries differ from each other, during the action of the mechanism of pure compression, vertebral compression occurs and flexion mechanism causes distraction of the rear parts of the spine and injuries of joints, in reaction to stress in the upper part of the cervical spine injuries occur and fracture of endplates separating adjacent intervertebral discs. Yogananda and Stemper (2013) put forward the thesis that other biomechanical reaction results are to be obtained by applying axial compressive force to formulations, but by using a higher loading speed (Yoganandan et al., 2013).

Knowledge about the mechanisms of damage and of the cervical spinal column resulting from the instability in combat is essential in clinical practice. Anticipation and correct diagnosis of dysfunction and their classification as stability or instability is extremely important both in the prognosis and during first conservative treatment or surgical field hospitals. 


\section{CONCLUSION}

Irrespective of the seating of the soldier, in connection with displacement in the vertical axis, there is a high probability of hitting his head on the roof of the vehicle thereby a compressional injury to the cervical spine occurs. The effect of fastening belts is undoubtedly significant, since they protect the soldier before moving under the influence of mass forces and the head hitting hull fittings. The use of safety belts affect the trajectory of head movement in relation to the body, giving rise to displacement of the neck in the sagittal and lateral plane.

\section{REFERENCES}

1. Bambach M.R., Grzebieta R.H., McIntosh A.S., Mattos G.A. (2013), Cervical and thoracic spine injury from interactions with vehicle roofs in pure rollover crashes, Accident Analysis and Prevention $50,34-43$.

2. Brzozowski R., Guła P., Sanak T. (2014), The army security in the aspect of threats resulting from the use of improvised explosive devices, Red.: S. Kowalkowski, B. Bębenek, T. Całkowski, Postexplosion soft tissue injuries, National Defence University Publishing House, Warsaw (in polish).

3. Cronin D. (2014), Finite element modeling of potential cervical spine pain sources in neutral position low speed rear impact, Journal of the mechanical behavior of biomedical materials, 33, 55-66.

4. Cusick J.F., Yoganandan N. (2002), Biomechanics of the cervical spine 4: major injuries, Clinical Biomechanics, 17, 1-20.

5. Daffner R.H., Sciulli R.L., Rodriguez S.A., Protech J. (2006), Imaging for evaluation of suspected cervical spine trauma: a 2-year analysis, Injury: International Journal of the Care of the Injured, 37(7), 652-658

6. Denis, F. (1983), The three column spine and its significance in the classification of acute thorocolumbar spinal injuries, Spine, 8(8), 817-831.

7. DeWit J.A., Cronin D.S. (2012), Cervical spine segment finite element model for traumatic injury prediction, Journal of the Mechanical Behavior of Biomedical Materials, 10, 138-150.

8. Heider N, Denefeld V, Holzwarth A. (2010), Methods for the analysis of global IED effects on military vehicles, 5th European Survivability Workshop, Alesund Norway.

9. Hryciów Z., Borkowski W., Wysocki J., Rybak P., Wiśniewski A. (2013), Experimental researches of safety of armoured personnel carrier crew during collision with obstacle, The Archives of Automotive Engineering, 61, 87-96.

10. Ivancic, P.C., Pearson, A.M., Panjabi, M.M., Ito, S. (2004), Injury of the anterior longitudinal ligament during whiplash simulation, European Spine Journal, 13(1), 61-68.

11. Krzystała E., Mężyk A., Kciuk S. (2011a), Analysis of the influence of the blast on wheeled military vehicle and their crew, Fast Tracked Vehicles, 28(2), 99-110.
12. Krzystała E., Mężyk A., Kciuk S. (2011b), Analysis of threat to crew posed by explosion of charge placed under wheeled armoured vehicle, Jouranl of Science of the Gen. Tadeusz Kosciuszko Military Academy of Land Forcs, 1(159) , 145-154.

13. Leahy P.D., Puttlitz Ch.M. (2012), The effects of ligamentous injury in the human lower cervical spine, Journal of Biomechanics, 45, 2668-2672.

14. Levine R.S. (1994), Head and Neck Injury, Society of Automotive Engineers, USA.

15. Nilakantan G. Tabiei A. (2009), Computational Assessment of occupant Injury Caused by Mine Blasts underneath Infantry Vehicles, Int. J. Vehicle Structures \& Systems, 1(1-3), 50-5.

16. Operating Instructions, description and use (2005), $8 \times 8$ Wheeled Armored ROSOMAK Tower HITFIST $30 \mathrm{~mm}$, Wojskowe Zakłady Mechaniczne S.A, Siemianowice Slaskie.

17. Panjabi, M.M., Maak, T.G., Ivancic, P.C., Ito, S. (2006), Dynamic intervertebral foramen narrowing during simulated rear impact, Spine, 31(5), 128-134.

18. Pintar F.A, Yoganandan N., Voo L. (1998), Effect of age and loading rate on human cervical spine injury threshold, Spine Sep, 15;23(18), 1957-62.

19. Protocol HFM-090/TG-25 (2007), The mine detonation process and occupant loading.

20. Ramasamy A., Masouros S.D., Newell N., Hill A.M. (2011), Proud W.G., Brown K.A., Bull A.M.J., Clasper J.C., In-vehicle extremity injuries from improvised explosive devices: current and future foci, Phil. Trans. R. Soc., 366, 160-170.

21. Robertson A., Branfoot T., Barlow I.F., Giannoudies P.V. (2002), Spinal injury patterns resulting from car and motorcycle accidents, Spine, 27(24), 2825-2830.

22. Schmitt K.-U., Niederer P., Muser M., Walz F. (2010), Trauma Biomechanics, Third Edition, Springer, Berlin.

23. Sławiński G. (2012), Pictures of AMV Rosomak after IED explosion, Afghanistan - own resources.

24. Sławiński G., Niezgoda T., Barnat W. (2013), Numerical analysis of the influence of blast wave on human body, Journal of KONES Powertrain and Transport, 20(3), 113-122.

25. Wojtkowski M., Ziółek J., Płomiński J., Waliński T. (2014), The army security in the aspect of threats resulting from the use of improvised explosive devices, Red.: S. Kowalkowski, B. Bębenek, T. Całkowski, Postexplosion analysis musculoskeletal injuries of Polish soldiers in military contingents - preliminary, National Defence University Publishing House, Warsaw (in polish).

26. Yang Y., Liou W.W., Sheng, J.Gorsich, D., Arepally, S., (2013) Shock wave impact simulation of a vehicle occupant using fluid/structure/ dynamics interactions, International Journal of Impact Engineering, 52, 11-22.

27. Yoganandan N., Stemper B.D., Pintar F.A., Maiman D.J., McEntire B.J., (2013), Chancey V.C., Cervical spine injury biomechanics: Applications for under body blast loadings in military environments, Clinical Biomechanics, 28, 602-609.

This investigation was supported by a research grant, as a part of the project DOBR-BIO4/022/13149/2013 financed by NCBiR. 